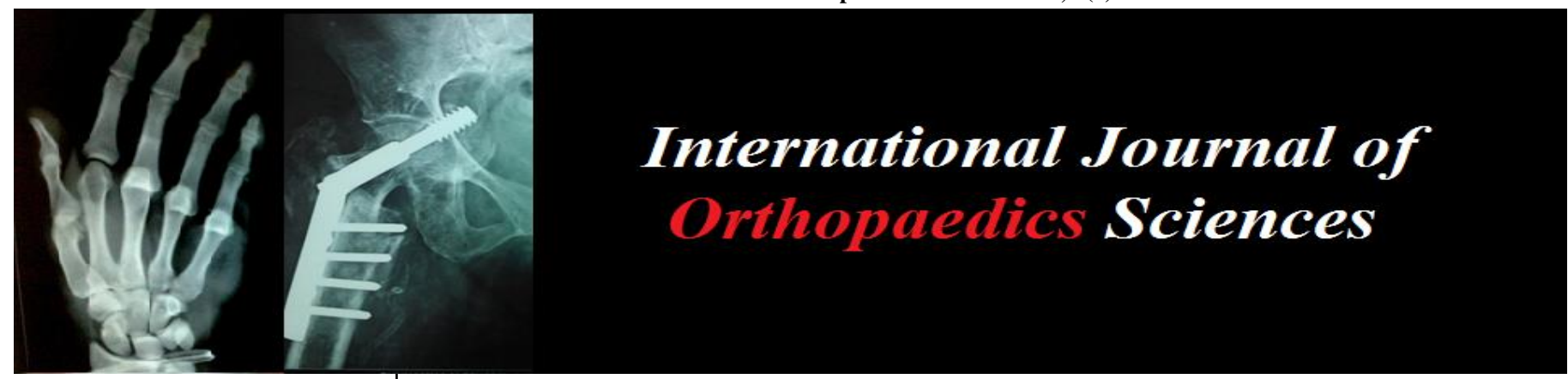

ISSN: $2395-1958$

IJOS 2019; 5(3): 214-219

(C) 2019 IJOS

www.orthopaper.com

Received: 21-05-2019

Accepted: 25-06-2019

Dr. Pratik Sidhdhapuria

Senior Resident Orthopedic

Department, Government

Medical College, Surat, New Civil

Hospital, Surat, Gujarat, India

Dr. Shahruhkhan Pathan

Senior Resident Orthopedic

Department, Government

Medical College, Surat, New Civil

Hospital, Surat, Gujarat, India

Dr. Vijay Chaudhary

Senior Resident Orthopedic

Department, Government

Medical College, Surat, New Civil

Hospital, Surat, Gujarat, India

\section{Study of functional and radiological outcomes of hip arthroplasty via posterior approach}

\author{
Dr. Pratik Sidhdhapuria, Dr. Shahruhkhan Pathan and Dr. Vijay \\ Chaudhary
}

DOI: https://doi.org/10.22271/ortho.2019.v5.i3d.1534

\section{Abstract}

Many surgical approaches to hip have evolved over the period of time surgical approaches differs chiefly in position of patient in supine or lateral and whether the hip is dislocated anteriorly or posteriorly. However most of the surgeon prefer approach where hip is dislocated posteriorly, patient in lateral position.

In this study we try to evaluate the clinical, radiological and functional outcome of hemi-replacement and total hip replacement operated by posterior approach.

No significant difference was found in limb length discrepancy. No peri prosthetic fractures were seen. Dislocation rate was 10 percent with posterior approach. No post-operative lurch was found with posterior approach.

Keywords: hemireplacement arthroplasty (Hra), total hip arhtroplasty (Tha/Thr), sickle cell anemia

\section{Introduction}

The normal hip functions as a "ball-and-socket" joint. The femoral head (ball) articulates with the acetabulum (Socket), allowing smooth range of motion in multiple planes. Any condition that affects either of these structures can leads to deterioration of the joint. This, in turn, can lead to deformity, pain and loss of functions. The most common condition affecting the hip joint in this way is osteoarthritis. Other conditions affect the hip joint adversely include idiopathic osteonecrosis, alcohol induced and other secondary osteonecrosis. Inflammatory arthritis (Rheumatoid arthritis, psoriatic arthritis, spondyloarthropathies, etc), developmental dysplasia, childhood hip disorders \& trauma ${ }^{[1]}$.

Total Hip Arthroplasty (THA) is a procedure whereby the diseased articular surfaces are replaced with synthetic materials, thus relieving pain and improving joint kinematics and function $^{[18]}$

Hemireplacement Arthroplasty (HRA) is a procedure in which femoral component is replaced by prosthesis, commonly in cases on neck of femur fractures ${ }^{[18]}$.

Many surgical approaches to hip have evolved over the period of time surgical approaches differs chiefly in position of patient in supine or lateral and whether the hip is dislocated anteriorly or posteriorly. The choice of surgical approaches is largely depending on personal preference and training. Posterior is the most commonly used surgical approaches. It is feared with increased rate of postoperative hip dislocation by posterior approach Although long term results of this differing approaches are unknown at his point short term benefits of some approaches have been reported ${ }^{[2]}$.

Arthroplasty surgeons remained discordant in their choice between approaches.

In this study we try to evaluate the clinical, radiological and functional outcome of hemi replacement and total hip replacement operated by posterior approach.

\section{Aims}

- To evaluvate the clinical, radiological and functional outcome of hemi-replacement and total hip arthoplasty by posterior approach

- To determine safety and efficacy of the approach
Senior Resident Orthopedic

Department, Government

Medical College, Surat, New Civil

Hospital, Surat, Gujarat, India 
- To determine significant predictors of complications

\section{Inclusion criteria}

1. All patients operated for hip arthroplasty giving informed consent for the trial will be included in the study

2. Outside the home ambulatory patient before fracture

3. non-pathological neck femur fracture

4. Avascular necrosis of hip

\section{Material and Methods}

- 30 patients operated for total hip or hemi arthoplasty posterior approach

- Position: lateral
- Anaesthesia: Spinal or general

- Antibiotics: Prophylactic antibiotic half an hour before surgery and to be continued for 48 hours after surgery.

- Stitch Removal: 12 to 15 days

- Dressing on $2^{\text {nd }}$ day (Removal of suction drain) and $7^{\text {th }}$ day

- Evaluation: On Basis of intra operative notes, Harris Hip Score and radio graphical evaluation

Follow UP: On 1 Month, 3 Month and 6 Months

\section{Surgical approach}

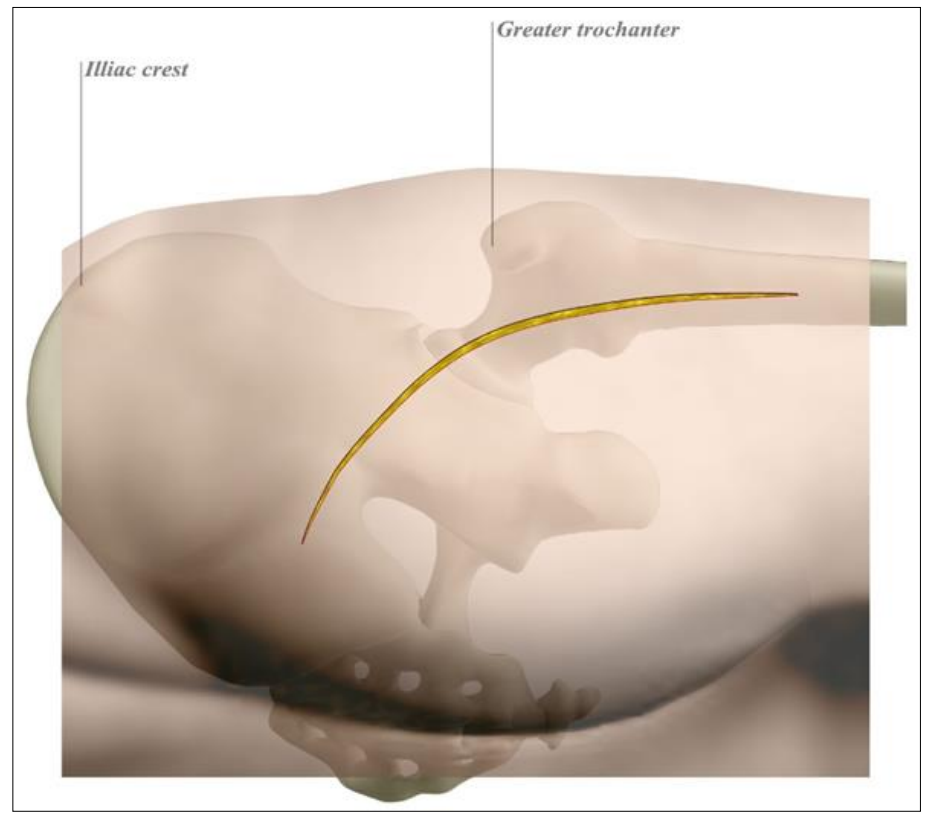

Fig 1: Incision-make 10 to $15 \mathrm{~cm}$ curved incision 0n posterior edge of greater trochanter (GT).

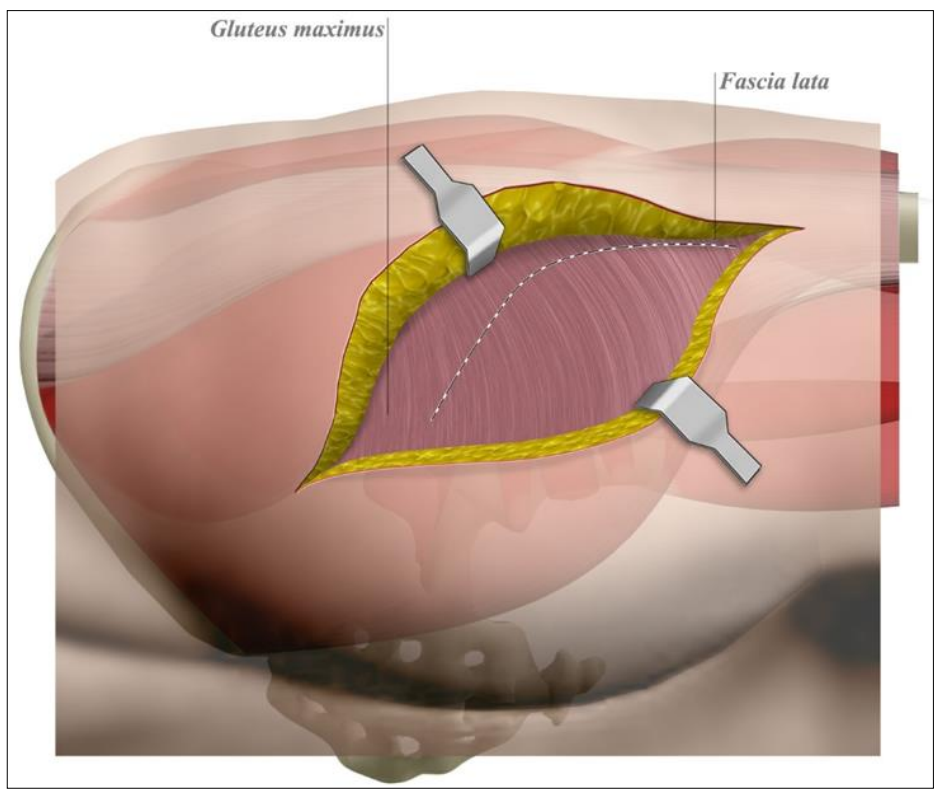

Fig 2: Begin $7 \mathrm{~cm}$ above and posterior to GT. curve posterior to the GT and continue down shaft of femur.

Superficial dissection-incise fascia lata to uncover vastus lateralis distally. Lengthen fascial incision in line with skin incision. Split fibers of gluteus maximus in proximal incision. Cauterize vessels during split to avoid excessive blood loss.
Deep dissection-internally rotate the hip to place the short external rotators on stretch. Place stay suture in piriformis and obturator internus tendon (Short external rotators) 


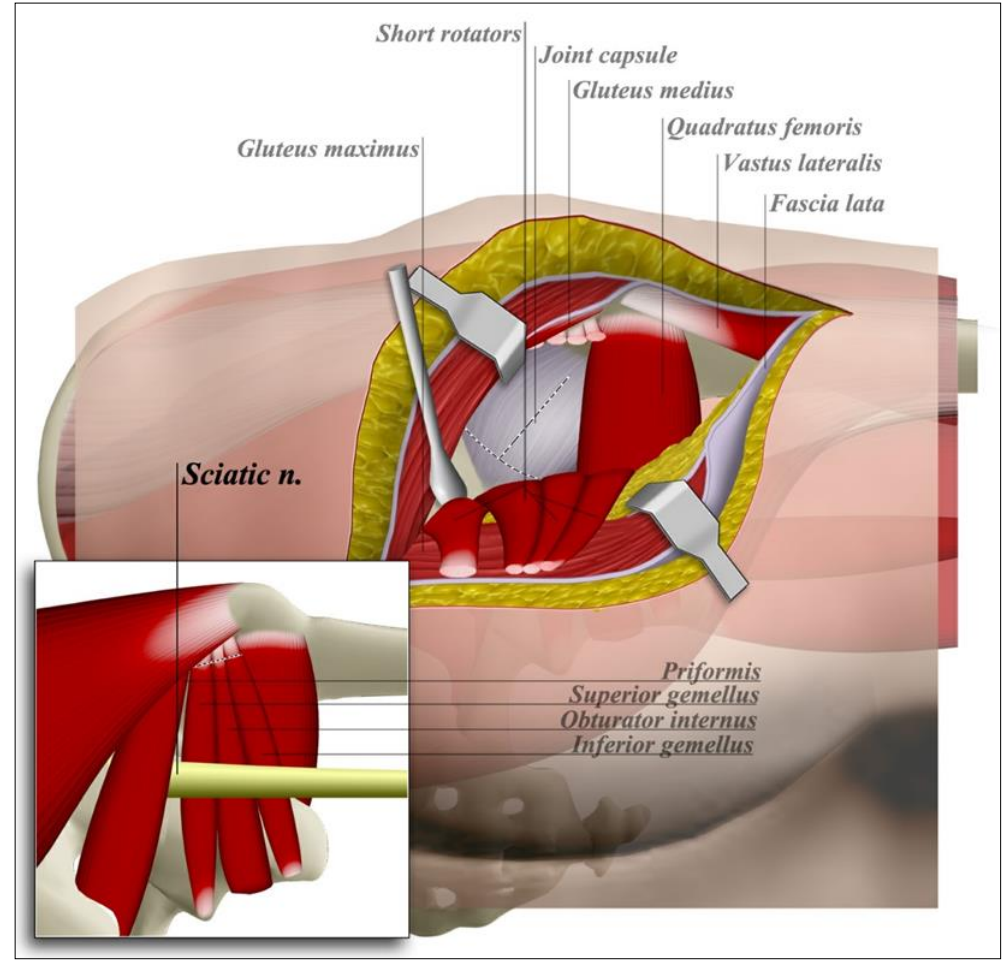

Fig 3

Detach piriformis and obturator internus close to femoral insertion. Reflect backwards to protect sciatic nerve. Incise capsule with longitudinal or $\mathrm{T}$-shaped incision. Dislocate hip with internal rotation after capsulotomy.

Proximal extension-may extend proximal incision towards iliac crest for exposure of ilium.

Distal extension-extend incision distally down line of femur down to level of knee. Vastus lateralis may either be split or elevated from lateral intermuscular septum.

Closure done in double layer with myodesis of short external rotators.

\section{Modified harris hip score ${ }^{[23]}$ \\ Pain}

None/ignores (44points)

Slight, occasional, no compromise in activity (40 points)

Mild, no effect on ordinary activity, pain after activity, uses aspirin (30 points)

Moderate, tolerable, makes concessions, occasional codeine (20 points)

Marked, serious limitations (10 points)

Totally disabled ( 0 points)

\section{Function: Gait}

Limp

None (11 points)

Slight (8 points)

Moderate ( 5 points)

Severe (0 points)

Unable to walk (0 points)

\section{Support}

None (11 points)

Cane, long walks ( 7 points)

Cane, full time (5 points)

Crutch (4 points)

2 Canes (2 points)

2 crutches (1 points)

Unable to walk (0 points)
Distance walked

Unlimited (11 points)

6 blocks (8 points)

2-3 blocks (5 points)

Indoors only ( 2 points)

Bed and chair (0 points)

\section{Functional activities}

Stairs

Normally (4 points)

Normally with banister ( 2 points)

Any method (1 points)

Not able ( 0 points)

\section{Socks/Shoes}

With ease (4 points)

With difficulty (2 points)

Unable (0 points)

\section{Sitting}

Any chair, 1 hour (5 points)

High chair, $1 / 2$ hour ( 3 points)

Unable to sit, $1 / 2$ hour, any chair (0 points)

\section{Public transportation}

Able to enter public transportation (1 points)

Unable to use public transportation ( 0 points)

Absence of deformity (All yes=4; less than 4=0)

1. Less than $30^{*}$ fixed flexion contracture

2. Less than $10 *$ fixed abduction

3. Less than $10^{*}$ fixed internal rotation in extension

4. Limb length discrepancy less than $3.2 \mathrm{~cm}$

\section{Range of motion score}

Flexion

Adduction

Abduction

External rotation

Internal rotation 
Scale: $211-300(5) ; 161-210(4) ; 101-160(3) ; 61-100(2) ; 31-$ 60(1); 0-30(0)

\section{Total Harris hip score}

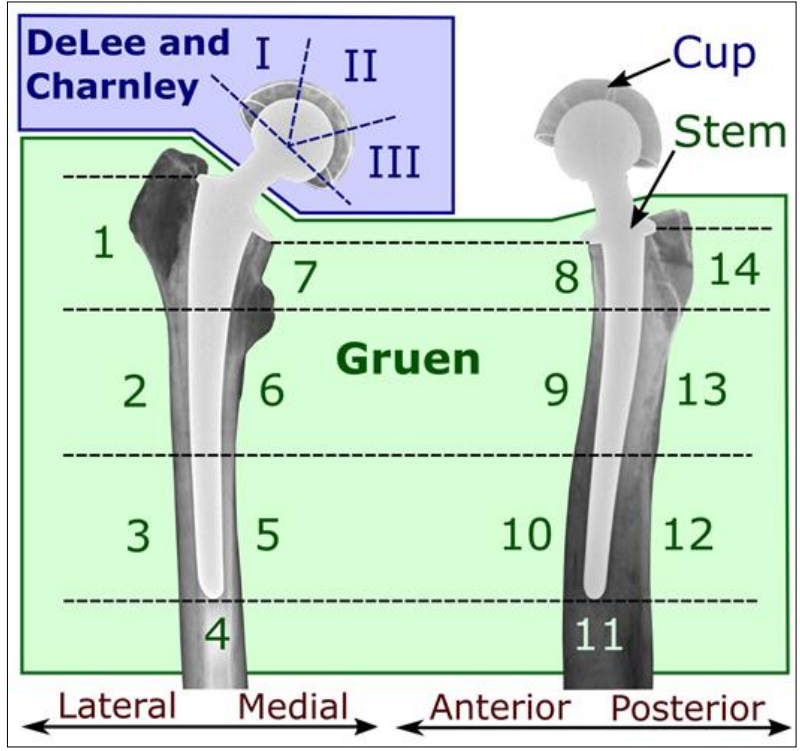

Fig 4: Hip prosthesis zones

Table 1: Radiological evaluation of Total HIP Arthroplasty

\begin{tabular}{|c|c|c|c|c|}
\hline & & $\begin{array}{l}6 \\
\text { weeks }\end{array}$ & $\begin{array}{l}3 \\
\text { months }\end{array}$ & $\begin{array}{l}6 \\
\text { months }\end{array}$ \\
\hline 1 & Limb length discrepancy & & & \\
\hline 2 & The horizontal center of rotation & & & \\
\hline 3 & The vertical center of rotation & & & \\
\hline 4 & The acetabular inclination & & & \\
\hline 5 & Stress shielding & & & \\
\hline 6 & The acetabular antiversion & & & \\
\hline 7 & Femoral stem positioning & & & \\
\hline 8 & Cement mantle & & & \\
\hline 9 & Spot welding & & & \\
\hline 10 & $\begin{array}{l}\text { Subsidence of stem/migration of acetabular } \\
\text { component }\end{array}$ & & & \\
\hline 11 & Other positive finding & & & \\
\hline
\end{tabular}

\section{Results}

Table 2: Functional Outcome

\begin{tabular}{|c|c|c|c|}
\hline & N & Mean & Std. Deviation \\
\hline Harris hip score 3 month & 30 & 87.96 & 4.1 \\
\hline Harris hip score 6 month & 30 & $92 . .27$ & 3.2 \\
\hline
\end{tabular}

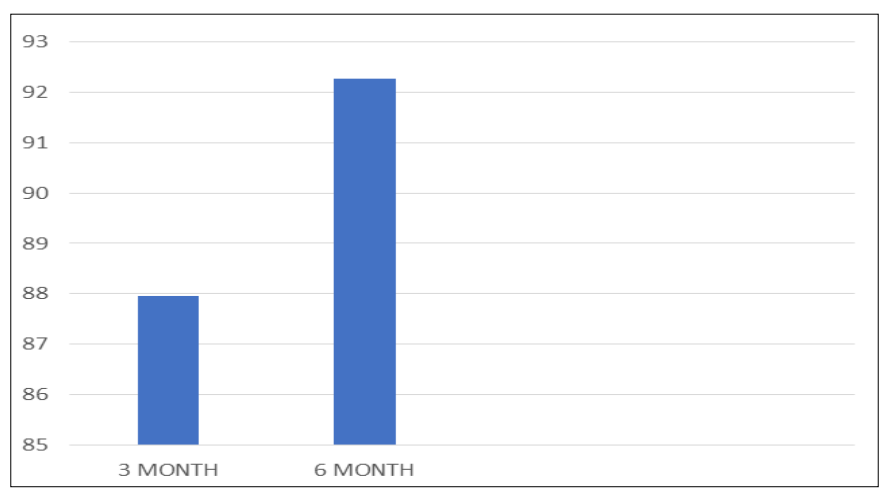

Fig 5: Harris hip score
Table 3

\begin{tabular}{|c|c|}
\hline Surgery type & Posterior approach \\
\hline \multicolumn{2}{|c|}{ Lurch } \\
\hline HRA & $8.33 \%$ \\
\hline THR (cemented) & $10 \%$ \\
\hline THR (Uncemented) & $12.5 \%$ \\
\hline \multicolumn{2}{|c|}{ Dislocation } \\
\hline HRA & $0.00 \%$ \\
\hline THR (Cemented) & $20 \%$ \\
\hline THR (Uncemented) & $12.5 \%$ \\
\hline
\end{tabular}

- Dislocation rate was 10 percent (3 patients) with posterior approach.

- Post-operative lurch was found not significant in our study

Table 4: Femoral Stem Positioning

\begin{tabular}{|c|c|c|c|c|c|}
\hline & & Center & Varus & Valgus & Total \\
\hline & Counts & 22 & 6 & 2 & 30 \\
\hline $\begin{array}{c}\text { Posterior } \\
\text { Aproach }\end{array}$ & $\begin{array}{c}\% \\
\text { Within }\end{array}$ & $73.33 \%$ & $20 \%$ & $667 \%$ & $100 \%$ \\
\hline
\end{tabular}

Femoral Stem Was Found Eccentric in 26.67 Perecent of Cases in Posterior Approach

Table 5: Limb length discrepancy

\begin{tabular}{|c|c|c|}
\hline Surgery type & $\mathbf{N}$ & Average lld \\
\hline HRA & 12 & $0.36 \mathrm{~cm}$ \\
\hline THR (Cemented) & 10 & $0.6 \mathrm{~cm}$ \\
\hline THR (Uncemented) & 8 & $0.5 \mathrm{~cm}$ \\
\hline
\end{tabular}

- No significant difference was found in limb length discrepancy in both approach

- No heterotropic ossification was seen in cases operated by posterior approach

- No peri prosthetic fractures were seen in cases operated by posterior approach

\section{Discussion}

- Total Hip Replacement/Hemiarthroplasty was performed as a mode of treatment in 30 selected patients by posterior approach in new civil hospital, surat. Hip replacement in all cases was performed in otherwise active individuals the age group ranged from 17 to 85 years. Such cases were followed up and evaluated clinically and radiologically.

- In our study, the follow up period was 6 months. All patients were alive at the last follow up. Coates and armor ${ }^{[34]}$ had reported a mortality of $29 \%, 7 \%$ were known to have died in the first month mainly due to medical complications like ischemic heart diseases, pulmonary embolism and septicemia complicating wound infection. In the later studies mortality reported was significantly reduced, Taine and armor 3\% at one month $10 \%$ at 6 months (1985), Delamarter and moreland [27] $12 \%$ at one year (1987), Gebhart et al. report a $0 \%$ in hospital mortality (1991). This has been attributable to advances in anaesthesia and critical care medicine and improvement in medical facilities.

- All the operations were performed in modular operation theatre with laminar airflow under antibiotic cover. This suggested that prophylactic antibiotic significantly reduced the rate of sepsis in conventional operation theater. This was based on the studies in favor of the use of systemic antibiotics, in orthopaedic surgery, by Bryan 
et al. Wilson et al. reported significant decrease in infection rate, when prophylactic antibiotics are used. In our study, superficial infection was detected in 5 patients. 1 patient had deep infection. All 6 patients were surgically debrided and treated with intravenous antibiotics according to culture sensitivity report for 2 weeks followed by oral antibiotics for 4 weeks. ${ }^{[17]}$

- Numerous approaches to the hip joint have been described, each claiming to have an advantage over the other.

- In our study we have used modified Gibson approach pioneered by kocher lenghenbach, in which short external rotators were tagged and cut capsule incised in \& hip dislocated posteriorly, capsule was closed in double layer.

- According to the Harris hip score $91 \%$ patients had well to excellent results in our study with mean score of 93 . Taine and armor had reported $70 \%$ good or excellent results, Gregory et al. ${ }^{[22]}$ reported a mean harris score of 83 with 6 patients having poor results (Score $<70$ ). But in 4 of these cases this was due to factors other than the hip itself.

- Only $9 \%$ patients complained of hip pain with $3 \%$ patient requiring regular analgesics. Coates and armour [22] reported $89 \%$ patients to be pain free or having mild pain whereas $11 \%$ had severe pain which limited function and for which patients required $76 \%$ patients to be pain free following operation.

- Post-operative lurch was not found significant in hip replacement done by this approach can be explained on the basis that abductors were not dissected. Marco Antonio et al. ${ }^{[19]}$

- Incidence of hip dislocation was found significantly high in patients operated by posterior approach $10 \%$, all cases were managed with closed reduction under anaesthesia and immobilization for 4 weeks. Tuberculosis, rheumatoid and sickle cell disease was associated with post-operative hip dislocation. No implant loosening was found. Rate of dislocation reported in various series was Coates and Armour ${ }^{[22]} 8 \%$, Sim and Stauffer ${ }^{[25]} 10.7 \%$, Cartlide ${ }^{[14]} 14.6 \%$, Taine and Armour 12.3\%, Dorr et al. $18 \%$ and Greenough and Jones $8 \%$.

- No subsidence or migration of the femur or acetabulum components was seen. There was no change in the orientation of the formal or acetabular components till last follow up. Stress shielding was found in 54\% of cases radiolucent zones were seen around the formal component in six cases which were non progressive till last follow up. Radiolucent shadow in all the above cases occupied $<50 \%$ area at the bone cement interface.

\section{Conclusion}

- At 6 Months Hip Score Was Found 93 In Posterior Approach

- Dislocation rate was 10 percent (3 patients) with posterior approach.

- Post-operative lurch and limb length discrepency were found not significant in our study

- Femoral stem was found eccentric in 26.67 perecent of cases in posterior approach

- No heterotropic ossification was seen in cases operated by osterior approach

- No peri prosthetic fractures or impplant loosening were seen in cases operated by posterior approach

- None of the patients in our study had complications of immobilsation like deep vein thrombosis, pneumonia atelectasis.

- Early mobilization with hip replacement and postoperative anti-coagulants was main reason for the significant reduction in these complications.

\section{References}

1. Charnley J. Arthroplasty of the hip. A new operation. Lancet. 1961; 1:1129-32. [PubMed]

2. Hip and knee replacements in Canada: 2012-2013 Quick Stats, 2013. [Accessed 2015 Feb. 12]. Available: www.cihi.ca/CIHI-ext portal/xlsx/internet/STATS_CJRR2012-2013_EN.

3. Light TR, Keggi K. Anterior approach to hip arthroplasty. Clin Orthop Relat Res. 1980; 152:255-60. [PubMed]

4. Chechik O, Khashan M, Lador R, et al. Surgical approach and prosthesis fixation in hip arthroplasty worldwide. Arch Orthop Trauma Surg. 2013; 133:1595600. [PubMed]

5. Siguier T, Siguier M, Brumpt B. Mini-incision anterior approach does not increase dislocation rate: a study of 1037 total hip replacements. Clin Orthop Relat Res. 2004; 426:164-73.

6. Evans Jonathan T, Evans Jonathan P, Walker Robert W, Blom Ashley W, Whitehouse Michael R, Sayers Adrian. How long does a hip replacement last? A systematic review and meta-analysis of case series and national registry reports with more than 15 years of follow-up. The Lancet. 2019; 393(10172):647-654. DOI: 10.1016/S0140-6736(18)31665-9.

7. Daniel Berry J, Jay Lieberman. Surgery of the Hip. Elsevier Health Sciences, 2012, p. 1035. ISBN 9781455727056.

8. Iain Watt, Susanne Boldrik, Evert van Langelaan and Robin Smithuis. Hip - Arthroplasty -Normal and abnormal imaging findings. Radiology Assistant. Retrieved. 2017.

9. Angerame Marc R, Fehring Thomas K, Masonis John L, Mason Bohannon J, Odum Susan M, Springer Bryan D. Early Failure of Primary Total Hip Arthroplasty: Is Surgical Approach a Risk Factor? The Journal of Arthroplasty. 2018; 33(6):1780-1785. Doi: 10.1016/j.arth.2018.01.014.

10. Meneghini Michael R, Elston Addison S, Chen Antonia F, Kheir Michael M, Fehring Thomas K, Springer Bryan D. Direct Anterior Approach. The Journal of Bone and Joint Surgery. 2017; 99(2):99-105. DOI:10.2106/JBJS.16.00060. PMID 28099299.

11. Displaced intracapsular hip fractures in fit, older people: a randomised comparison of reduction and fixation, bipolar hemiarthroplasty and total hip arthroplasty. Health Technol Assess, 2005.

12. Morrey BF, Ilstrup D. Size of the femoral head and acetabular revision in total hip-replacement arthroplasty. J Bone Joint Surg Am. 1989; 71(1):50-55.

13. Rose RM, Nusbaum HJ, Schneider H, Ries M, Paul I, Crugnola A, Simon SR, Radin EL. On the true wear rate of Ultra high-molecular-weight polyethylene in the total hip prosthesis. J Bone Joint Surg Am. 1980; 62(4):537549.

14. Hope PG, Kristinsson KG, Norman P, Elson RA. Deep infection of cemented total hip arthroplasties caused by coagulase-negative staphylococci. J Bone Joint Surg Br. $1989 ; 71(5): 851-855$. 
15. Welch RB, McGann WA, Picetti GD, 3rd Charnley lowfriction arthroplasty. A fifteen- to seventeen-year followup study. Orthop Clin North Am. 1988; 19(3):551-555.

16. Russotti GM, Coventry MB, Stauffer RN. Cemented total hip arthroplasty with contemporary techniques. A fiveyear minimum follow-up study. Clin Orthop Relat Res. 1988; (235):141-147.

17. Severt R, Wood R, Cracchiolo A, 3rd, Amstutz HC. Long-term follow-up of cemented total hip arthroplasty in rheumatoid arthritis. Clin Orthop Relat Res. 1991; (265):137-145

18. Maloney WJ, Jasty M, Rosenberg A, Harris WH. Bone lysis in well-fixed cemented femoral components. J Bone Joint Surg Br. 1990; 72(6):966-970.

19. Harris WH, Maloney WJ. Hybrid total hip arthroplasty. Clin Orthop Relat Res. 1989; (249):21-29.

20. Hendel D, Yasin M, Garti A, et al. Fracture of the great trochanter during hip replacement: A retrospective analysis of 21/372 cases. Acta Orthop Scand. 2002; 73:295-7.

21. Dosanjh S, Matta J, Bhandari M. The final straw: a qualitative study to explore patient decisions to undergo total hip arthroplasty. Arch Orthop Trauma Surg. 2009; 129:719-27.

22. Woolson ST, Pouliot M, Huddleston J. Primary total hip arthroplasty using an anterior approach and a fracture table: short-term results from a community hospital. J Arthroplasty. 2009; 24:999-1005.

23. Mulliken BD, Rorabeck C, Bourne R, et al. A modified direct lateral appraoch in total hip arthroplasty: a comprehensive review. J Arthroplasty. 1998; 13:737-47.

24. Learmonth ID, Young C, Rorabeck C. The operation of the century: total hip replacement. Lancet. 2007; 370:1508-19.

25. Barber TC, Roger D, Goodman S, et al. Early outcome of total hip arthroplasty using the direct lateral vs the posterior surgical approach. Orthopedics. 1996; 19:873-5.

26. Witzleb WC, Stephan L, Krummenauer F, et al. Shortterm outcome after posterior versus lateral surgical approach for total hip arthroplasty: a randomized clinical trial. Eur J Med Res. 2009; 14:256-63.

27. Müller M, Thotz S, Springer I, et al. Randomized controlled trial of abductor muscle damage in relation to the surgical approach for primary total hip replacement: minimally invasive anterolateral versus modified direct lateral approach. Arch Orthop Trauma Surg. 2011; 131:179-89

28. Pfirrmann CW, Notzli H, Dora C, et al. Abductor tendons and muscles assessed at MR imaging after total hip arthroplasty in asymptomatic and symptomatic patients. Radiology. 2005; 235:969-76.

29. Twair A, Ryan M, O'Connell M, et al. MRI of failed total hip replacement caused by abductor muscle avulsion. AJR Am J Roentgenol. 2003; 181:1547-50.

30. Alecci V, Valente M, Crucil M, et al. Comparison of primary total hip replacements performed with a direct anterior versus the standard lateral approach: perioperative findings. J Orthop Traumatol. 2011; 12:123-9.

31. Restrepo C, Parvizi J, Pour A, et al. Prospective randomized study of two surgical approaches for total hip arthroplasty. J Arthroplasty. 2010; 25:671-9.e1.

32. Goebel S, Steinert A, Schillinger J, et al. Reduced postoperative pain in total hip arthroplasty after minimalinvasive anterior approach. Int Orthop. 2012; 36:491-8.
33. Bergin PF, Doppelt J, Kephart C, et al. Comparison of minimally invasive direct anterior versus posterior total hip arthroplasty based on inflammation and muscle damage markers. J Bone Joint Surg Am. 2011; 93:13928.

34. Meneghini RM, Pagnano M, Trousdale R, et al. Muscle damage during MIS total hip arthroplasty: SmithPeterson versus posterior approach. Clin Orthop Relat Res. 2006; 453:293-8. 